\title{
Novas TECNOLOGIAS DE VIGILÂNCIA \\ E A GESTÃO DE VIOLÊNCIAS $\star$
}

\author{
Irme Salete Bonamigo $\star \star$ \\ Universidade Comunitária Regional de Chapecó, Chapecó, SC, Brasil
}

\section{Resumo}

Este artigo discute as tecnologias de vigilância e controle como estratégia de gestão de violências, a partir do acompanhamento do projeto de instalação de câmeras de monitoramento eletrônico na cidade de Chapecó (SC). Trata-se de um estudo etnográfico, articulado com as contribuições da Teoria Ator-Rede, que abrangeu a investigação de quatro jornais locais, durante um ano, a realização de 31 entrevistas, a coleta de 32 documentos e a observação participante, com registro em diário de campo. A descrição dos eventos permitiu identificar a vinculação da categoria violência aos danos relacionados ao patrimônio público e privado e sua conexão com as novas tecnologias de vigilância e controle, a partir da mediação de três outras categorias: proteção, segurança e prevenção. O estudo busca contribuir com a discussão do tema violências na contemporaneidade, a partir da análise de redes que visam à produção de segurança, permitindo compreender e repensar práticas sociais e políticas públicas.

Palavras-chave: violência; teoria ator-rede; tecnologias de vigilância e controle; políticas públicas.

\section{NEW TECHNOLOGIES OF VIGILANCE}

\section{AND THE MANAGEMENT OF VIOLENCE}

\begin{abstract}
This article discusses the way technologies of violence and control are used as a strategy to manage violence, following attentively the installation of electronic vigilance cameras' project in the city of Chapecó. The ethnographic study comprised the investigation of four regional newspapers during a year, 31 interviews, the collecting of 32 documents and the participant observation with daily field notes. The description of the events permits to identify the link between the category of violence and the damages inflicted to public and private patrimony

^Artigo escrito com base na pesquisa de doutorado Violências na contemporaneidade: etnografias de redes sociotécnicas na cidade de Chapecó (SC), realizada no período de 2004 a 2007, sob a orientação do Prof. Dr. Ronald Arendt, com auxílio financeiro do CNPq (bolsa de doutorado), CAPES (bolsa de doutorado no exterior) e PCDTU - UNOCHAPECÓ, aprovada pela Comissão de Ética em Pesquisa da UERJ (COEP), documento no . 004/2007.

$\star \star$ Endereço para correspondência: Universidade Comunitária Regional de Chapecó UNOCHAPECÒ. Centro de Ciências Humanas e Sociais. Avenida Senador Attílio Fontana, 591-E, Bairro Efapi - Cep: 89809-000 - Caixa Postal: 747 - Chapecó - SC.

E-mail: bonamigo@unochapeco.edu.br
\end{abstract}


and its connection to the new technologies of violence and control, established upon the mediation of three other categories: protection, security and prevention. The study proposes to contribute to the discussion of the subject of violence in contemporaneity from the analysis of networks that aim to safety production, allowing us to understand and rethink social practices and public policies.

Keywords: violence; actor-network theory; technologies of vigilance and control; public policies.

\section{INTRODUÇÃo}

Chapecó é hoje a segunda cidade no estado de Santa Catarina com o maior número de câmeras de monitoramento (total de 186), sua população de 189. 052 mil habitantes (IBGE, 2010) convive em seu cotidiano com esses equipamentos, que frequentemente tornam-se destaque nos noticiários locais, como protagonistas ou coadjuvantes em investigações, como ferramenta de fiscalização de trânsito e inibição de crimes ou mesmo como alvos de depredação. Apesar da consolidação dessa tecnologia de vigilância e controle de violências, o seu uso no município é recente e fruto de um processo de elaboração de projeto, mobilização de atores e recursos para a aquisição dos equipamentos, que iniciou com uma câmera experimental em abril de 2005.

A pesquisa etnográfica que compõe este artigo abrange o acompanhamento da instalação dessa primeira câmera experimental, a elaboração do projeto de uso da tecnologia de vigilância e controle, a tentativa de mobilização de atores para a sua efetivação, a justificativa de sua importância e a legitimação da sua existência. Esses momentos e movimentos iniciais são privilegiados no estudo, pois discursos e ações estavam se configurando e controvérsias puderam ser acompanhadas enquanto a caixa-preta ${ }^{1}$ ainda estava aberta. Ou seja, hoje o uso de câmeras de monitoramento no município é um "fato", uma caixa-preta fechada, a rede que foi mobilizada para a sua implementação, a história junto com as dúvidas e as controvérsias que a acompanharam não estão mais visíveis. Entretanto, foi possível, por meio do estudo, acompanhar o seu processo de produção antes que ela se fechasse.

Assim, a partir do acompanhamento do projeto de instalação de câmeras de vigilância, articulado pelo poder público municipal de Chapecó, este artigo discute a questão da utilização de novas tecnologias de vigilância e controle, seguindo o seu vínculo com a constituição e mobilização contemporânea de coletivos para a gestão de violências. ${ }^{2}$

As novas tecnologias de vigilância e controle incluem dispositivos como câmeras e sistemas eletrônicos de monitoramento e identificação, radares, sensores de presença e de reconhecimento e compõem a contemporaneidade, marcada pela incerteza e imprevisibilidade (BECK, 2001), podendo ser depósito tanto das nossas esperanças, quando concebidas como desenvolvimento e segurança, como dos nossos maiores temores, quando associadas ao controle (PEDRO, 2005). 
Para situar e compreender as novas tecnologias na contemporaneidade, consideram-se, no decorrer do artigo, as noções de "sociedade disciplinar" e "governamentalidade", discutidas por Michel Foucault, de "subjetividade", forjada por Felix Guattari, de "sociedade de controle", proposta por Gilles Deleuze, e de "coletivo" e "rede sociotécnica", discutidas por Latour.

As novas tecnologias são aqui compreendidas como híbridos de humanos e não humanos, constituindo-se em uma nova instância de subjetivação coletiva.

[...] as máquinas tecnológicas de informação e de comunicação operam no núcleo da subjetividade humana, não apenas no seio das suas memórias, da sua inteligência, mas também da sua sensibilidade, dos seus afetos, dos seus fantasmas inconscientes. A consideração dessas dimensões maquínicas de subjetivação nos leva a insistir, em nossa tentativa de redefinição, na heterogeneidade dos componentes que concorrem para a produção de subjetividade [...] (GUATTARI, 1992, p. 14).

Desse modo, a subjetividade é concebida como produção e não como essência, constituindo-se de formas de agir, pensar, sentir e perceber a si e ao mundo, forjadas por diferentes dispositivos: econômicos, sociais, tecnológicos, ecológicos, etológicos, midiáticos, entre outros. Portanto, mais importante que o confronto com os dispositivos de vigilância e controle é a apreensão dos seus efeitos, das trocas múltiplas entre "indivíduo-grupo-máquina” (GUATTARI, 1992, p. 17).

\section{Metodologia}

Foi realizado um estudo etnográfico guiado pelos princípios, regras e propriedades metodológicas da Teoria Ator-Rede, que se situa no campo da Sociologia das Ciências e tem como fundadores Bruno Latour, John Law, Michel Callon, entre outros. Elegeu-se a instalação de câmeras de monitoramento no centro da cidade de Chapecó (SC) como um evento sociotécnico vinculado à gestão contemporânea de violências no município. Como estratégias metodológicas realizaram-se: 31 entrevistas com pessoas que compunham o coletivo investigado ou eram protagonistas do evento descrito; a observação participante do cotidiano cidade, com registro em diário de campo; pesquisa de reportagens sobre o tema em quatro jornais de circulação regional, durante um ano; e a coleta de 32 documentos (leis, relatórios, projetos, registro de ocorrências, entre outros).

\section{Articulando noções E APRESENTANDo o PROJETo ESTUdAdo}

O monitoramento eletrônico através de câmeras, em Chapecó, foi uma das propostas de ativação do Departamento de Defesa do Cidadão, criado em 2005, como forma de gerir as violências no município. A preocupação com as violências, a insegurança expressa nos discursos e os movimentos que buscam o seu controle teve seu ápice, em Chapecó, ${ }^{3}$ no final da década de 1990, quando houve uma explosão do tema na cidade, por meio de: veiculação de eventos violentos pela mídia; 
realização de debates e palestras; circulação de estatísticas vinculadas às práticas violentas ,de modo a sustentar a afirmação de seu aumento; e a constituição de vários coletivos tendo as violências como foco: Fórum Municipal e Catarinense pelo Fim da Violência e Exploração Sexual Infanto-Juvenil, Grupo de Estudos sobre Violência (NESVI), Grupo de Estudo e Pesquisa de Gênero Fogueira, Centro de Atendimento Integral às Crianças e Adolescentes Vítimas de Violência e Exploração Sexual (CEVIVI), Fórum Chapecoense de Estudos e Combate à Violência (FECOV), Polícia Comunitária (PC) e Fórum Permanente pela Paz.

Concomitante a esses eventos, houve a configuração de novos movimentos por parte dos governos municipal e estadual, para o controle e gestão das violências em Chapecó. Entre eles, destacam-se a criação da Diretoria de Defesa do Cidadão (que, em 2010 tornou-se Secretaria de Defesa do Cidadão) e o projeto de câmeras de monitoramento eletrônico. A estratégia de criação desses novos coletivos, para prevenir violências, conecta em suas redes sociotécnicas tanto novas tecnologias de vigilância e controle como os sentimentos de insegurança e medo, ou a percepção do risco de sofrer práticas violentas, por parte da população da cidade.

A noção de coletivo fundamenta-se em Latour (2001) e enfatiza as associações entre humanos e não humanos, sendo considerada uma expressão mais adequada que a palavra sociedade, predominantemente utilizada para evidenciar relações sociais, das quais os não humanos são excluídos. O termo não humano é empregado pelo autor para referir equipamentos, materiais, artefatos de inscrição e armazenamento de dados científicos, dentre outros. Para Latour, a sociedade torna-se incompreensível sem a presença dos não humanos. Além disso, o termo actante é empregado como sinônimo de agente e ator para abranger também os não humanos. Um actante pode ser definido como qualquer pessoa, instituição ou coisa que tenha agência, que produza efeito na rede: "[...] a única maneira de definir um ator é por intermédio de sua atuação; assim também, a única maneira de definir uma atuação é indagar em que outros foram modificados, transformados, perturbados ou criados pela personagem em apreço" (LATOUR, 2001, p. 143).

$\mathrm{O}$ conceito de rede tem sua origem na topologia e pode ser caracterizada como uma totalidade aberta capaz de crescer para todos os lados e direções, sendo seu único elemento constitutivo o nó. Ela deve ser compreendida como base em uma lógica das conexões e não das superfícies. Dessa forma, segundo Kastrup (2004, p. 80), "pouco importam as suas dimensões. Pode-se aumentá-la ou diminuí-la sem que perca suas características de rede, pois ela não é definida por sua forma, por seus limites extremos, mas por suas conexões, por seus pontos de convergência e de bifurcação".

Latour (2006, p. 192) concebe rede como uma ferramenta para descrever as associações heterogêneas, sendo marcada pelos seguintes aspectos: a) um conjunto de pontos que se encontram conectados: essas conexões são traçáveis e podem ser empiricamente seguidas; b) entre as conexões há vazios; c) conservar essas conexões demanda esforço; d) a rede é o traço deixado, por uma circulação, pela tradução. A noção de tradução é definida por Latour (2001, p. 356) para referir "o trabalho graças ao qual atores modificam, deslocam e transladam seus vários 
e contraditórios interesses". Considerando que, na composição de uma rede, os atores se unem em função de interesses em comum, pode-se dizer que a tradução acontece quando um ator translada o interesse dos demais por meio da produção de novas interpretações e deslocamentos, envolvendo-os na construção da rede.

A descrição do coletivo, a seguir, implica o acompanhamento da rede que o sustenta e a ação dos actantes, a partir do referencial teórico-metodológico da Teoria Ator-Rede. ${ }^{4}$

\section{A COMPOSIÇÃo do COLETIVo}

A ideia de um cidadão seguro sustentou a criação da Diretoria de Defesa do Cidadão na administração do governo municipal 2005-2008, constituindo-se em uma estratégia de gestão de violências por meio de dispositivos de segurança, como o monitoramento através de vídeos e câmeras. É importante situar que o governo municipal eleito em 2005 foi reeleito para o período 2009-2012 e, a partir de outra composição, mantém-se atualmente na gestão.

Foucault (2003) nos ajuda a compreender essa forma contemporânea de governar a partir de dispositivos de segurança. $\mathrm{O}$ autor analisa as grandes formas de governo no Ocidente: (1) o Estado de justiça, "nascido em uma territorialidade do tipo feudal e que correspondia, em geral a uma sociedade da lei - leis costumeiras e leis escritas - com todo o jogo de engajamento e de litígios" (FOUCAULT, 2003, p. 304); (2) o Estado administrativo, "nascido nos séculos XV e XVI, em uma territorialidade de tipo fronteiriça e não mais feudal [...] que correspondia a uma sociedade de regulamentos e disciplinas" (FOUCAULT, 2003, p. 304-305); (3) o Estado de governo, que corresponde ao vigente e existe graças a governamentalidade, "que não é mais definido por sua territorialidade, pela superfície ocupada, mas por uma massa: a massa da população, com seu volume, sua densidade, com certamente, o território sobre o qual ela se estende, mas que não é dela senão um componente" (FOUCAULT, 2003, p. 305). Foucault (2003, p. 305) considera esse Estado de governo "que se apóia essencialmente sobre a população e que se refere e utiliza a instrumentação do saber econômico, corresponderia a uma sociedade controlada pelos dispositivos de segurança".

Portanto, Foucault (2003, p. 303) define governamentabilidade como:

[...] o conjunto constituído pelas instituições, procedimentos, análises e reflexões, cálculos e táticas que permitem exercer essa forma bem específica, bem complexa de poder, que tem como alvo principal a população, como forma mais importante de saber, a economia política, como instrumento técnico essencial, os dispositivos de segurança.

Porém, se no Brasil a segurança do município é responsabilidade do governo estadual e federal, de que forma essa proposta do governo municipal pode operacionalizar-se? 
Da forma que a lei permite, que a prefeitura incentive esse ou dê esse aporte. Então, de acordo com a Constituição Federal, sem ir contra a Constituição Federal ou Estadual, buscar mecanismos municipais para atender melhor a comunidade com relação à segurança. Dar aquela tranqüilidade, psicologicamente mostrar para elas que está mais seguro a situação daquele município (ACTANTE R). ${ }^{5}$

Percebe-se que a construção da ideia e da imagem de que o município é um lugar seguro é tratada como central na gestão das violências e envolve procedimentos e equipamentos produtores de subjetividade, ou seja, produtores de "sensação de segurança" para as pessoas que vivem nesse espaço. Um dos procedimentos pensados é a vigilância dos pontos onde ocorrem conflitos, a proteção do cidadão e do patrimônio público e privado, e a administração da circulação de pessoas e veículos no espaço urbano, por meio da instalação de câmeras de monitoramento eletrônico, inicialmente no centro da cidade,

A instalação desses equipamentos foi uma das promessas de campanha do candidato a prefeito, em 2004, reafirmando a sua intenção logo após a eleição:

Também vamos implantar o monitoramento através de câmaras de vídeo na área central da cidade. Isso vai possibilitar o deslocamento de parte do efetivo do centro para os bairros. A guarda de trânsito também terá a função de 'guarda municipal' para proteger o nosso patrimônio público. (Prefeito eleito, em entrevista ao Diário da Manhã, publicada em 16 e 17 de outubro de 2004).

$\mathrm{O}$ discurso do prefeito torna evidente a função de vigilância delegada às câmeras de monitoramento, já que elas são citadas como uma forma de substituir os policiais. Segundo Latour (2001, p. 216), o processo de delegação envolve três deslocamentos: (1) atorial (as câmeras de monitoramento constituem um novo personagem que produz determinados efeitos: não são mais os policiais militares); (2) espacial (na Rua X agora mora o novo actante); e (3) temporal (as câmeras de monitoramento estão ali dia e noite substituindo os policiais, que estão em outro lugar).

O Projeto de Instalação das Câmeras de Monitoramento, em Chapecó, envolveu os seguintes actantes: a tecnologia do monitoramento eletrônico; a Prefeitura Municipal, por meio da Diretoria da Defesa do Cidadão; o governo do Estado, através da Polícia Militar, responsável pelo monitoramento das imagens; a Câmara de Dirigentes Lojistas (CDL); e a Associação Comercial e Industrial de Chapecó (ACIC), que buscaram mobilizar recursos entre os empresários. Envolveu, ainda, três empresas privadas que participaram da instalação experimental realizada em abril de 2005: uma empresa de segurança (A) responsável pela instalação do sistema e manutenção; uma empresa de informática (B) que forneceu o equipamento para armazenar as imagens; e outra empresa de informática (C) que forneceu os computadores. 
A lista dos actantes conduz a algumas indagações: quais foram os interesses dos diferentes actantes envolvidos no projeto? Como esses interesses foram traduzidos para a composição da rede? Quais ações de cada actante?

O monitoramento eletrônico através de câmeras foi pensado como forma de gerir as violências no município, constituindo um dispositivo de segurança, conforme analisa Foucault, e uma tecnologia de vigilância.

De forma sucinta, pode-se dizer que a nova vigilância estende os sentidos e tem pouca visibilidade para o sujeito, embora se fundamente na visibilidade do sujeito. É, em grande medida, involuntária e integrada à atividade cotidiana. Estrutura-se na conexão com as novas tecnologias, sendo freqüentemente mediada por meios remotos e estando disponível de forma contínua, em tempo real. Através dela é fácil combinar dados, armazená-los, analisá-los e mesmo recuperá-los a qualquer instante. (PEDRO, 2005, p. 13).

Uma câmera experimental foi instalada no cruzamento da rua Marechal Deodoro com a rua Getúlio Vargas, no centro de Chapecó. E os cabos de monitoramento foram puxados até a base da Polícia Militar, situada próxima a esse cruzamento. Essa fase experimental teve como objetivo mobilizar pessoas e recursos para viabilizar a implantação do projeto. "essa câmera está direcionada [...] ao trânsito, [...] ao problema dos furtos, mas juntando o problema do trânsito e o problema dos furtos, você tem que ver que isso está direcionado aos empresários de Chapecó. Que são os lojistas, no caso" (ACTANTE I).

Apesar de os empresários de Chapecó demandarem monitoramento eletrônico, não havia ainda um consenso sobre os recursos que os mesmos disponibilizariam para a execução do projeto, por isso a necessidade de mobilização destes. O Clube dos Diretores Lojistas (CDL) e a Associação Comercial e Industrial de Chapecó (ACIC) são as entidades representativas dos empresários e, durante o período de realização da pesquisa, não tinham claro, ainda, as suas contribuições, pois o projeto beneficiaria, naquele momento, apenas os empresários localizados no trajeto previsto, o que gerava dissenso.

Com relação aos recursos públicos a serem investidos pelo governo municipal também não havia consenso "[...] claro, vai ter as controvérsias. Porque daqui a pouco seria um investimento que poderia estar sendo utilizado em uma outra área, que de repente está com deficiência, daqui a pouco na área de saúde, na área..." (ACTANTE I).

O recurso para a execução do projeto tornou-se um actante com força para consolidar ou fragilizar a rede, mobilizar ou desmobilizar outros actantes, sendo objeto de controvérsias. No entanto, os interesses do governo municipal, das entidades representativas dos empresários e da Polícia Militar eram comuns no que se refere ao controle de práticas violentas no centro da cidade, o que possibilitou a formação da rede naquele momento. 
A Polícia Militar (PM) concebia o monitoramento eletrônico como "mais um recurso para a segurança pública do nosso município" (ACTANTE G) e compreendia que a prefeitura, em parceria com os empresários, seria responsável pela implantação do sistema, enquanto que a PM operaria o mesmo. O projeto previa inicialmente fazer um segundo piso na base da Polícia Militar, localizada no centro, e implantar nele todo o sistema de monitoramento das imagens, instalar seis câmeras na avenida central até o terminal urbano e, posteriormente em ruas transversais, em escolas centrais e na praça, formando um circuito de TV, que cobriria todo o centro da cidade e abrangeria um total de 12 câmeras. Depois, o sistema seria expandido para os bairros. Todo o monitoramento das imagens seria feito por policiais militares: "A nossa participação é fazer funcionar o sistema. [...] é colocar o homem, a pessoa para operar. E utilizar esse como mais um recurso para a segurança pública do nosso município" (ACTANTE G).

$\mathrm{O}$ arquivamento das imagens seria realizado da seguinte forma:

Por exemplo, uma câmera que nós temos aqui, ela grava 24 horas, durante 20 dias ininterruptos. Aí gravou 20 dias, então a primeira imagem lá começa a gravar em cima. No computador. E se eu quiser guardar essa imagem então vou ter que gravar em disquetes ou em CD. Mas, só vou gravar se tiver alguma imagem que me interessa. $\mathrm{O}$ arquivamento seria feito pelas pessoas que estivessem operando o sistema e que vissem alguma imagem que fosse importante ou interessante, ele iria salvar essa imagem. Então, você pode salvar tanto em $\mathrm{CD}$, quanto no próprio equipamento, no computador. (ACTANTE G).

Observa-se que cabe ao operador decidir qual pessoa considerar suspeita para acionar os policiais, qual imagem arquivar ou descartar. A figura do operador torna visível que o funcionamento das câmeras de monitoramento eletrônico é sustentado por uma rede de humanos e não humanos e o controle possibilitado é um efeito dessa rede como um todo.

Com relação ao operador, cabe ainda perguntar: a partir de que referências ele vai eleger as pessoas suspeitas? Acompanhemos um caso relatado pelo actante $\mathrm{R}$ :

"três adolescentes foram nas Casas Pernambucanas, sentaram ali próximo com uma bolsa. Aí o cara olhou na tela, chamou recurso e os policiais foram lá e abordaram os jovens [...] E na bolsa não tinha alicate, nem martelo, tinha cachaça" (ACTANTE Z).

Pode-se indagar sobre a aparência dos três adolescentes que foram considerados suspeitos. Pedro (2005) chama a atenção para a necessidade de analisar os esquemas de interpretação que guiam o juízo dos operadores e cita que, na Inglaterra, os operadores de câmera geralmente escolhem homens, jovens e negros. 
Voltando para a discussão dos diferentes actantes envolvidos no projeto de instalação das câmeras de monitoramento eletrônico, passo a analisar a participação da empresa de segurança e das empresas de informática na fase experimental. A empresa privada de segurança (A) foi convidada pela Diretoria de Defesa do Cidadão e se propôs a instalar, em nível experimental, a câmera de vídeo com monitoramento eletrônico e, em conjunto com a Diretoria de Defesa do cidadão, convidou duas empresas de informática $(\mathrm{B}$ e $\mathrm{C}$ ) para participarem do projeto. As empresas $\mathrm{B}$ e $\mathrm{C}$ foram convidadas devido às ligações políticas com a Diretoria de Defesa do Cidadão e comerciais com a Empresa A e participaram, nessa fase, cedendo equipamentos, conforme explica o actante I:

Até porque os dois hoje, tanto a $\mathrm{B}$ como a $\mathrm{C}$ são parceiras da Empresa A, em termos de vendas de equipamentos, tudo isso, área de computadores, área de informática, a gente pega, toda a nossa compra é feita com essas empresas aí. Por isso dessa parceria. Claro, no geral eles estão direcionados a essa venda de equipamentos. (ACTANTE I).

A Empresa A ficou responsável pela parte técnica e comercial do projeto: "A parte técnica de instalação é toda a nossa responsabilidade. Vai fazer, no caso, a venda, que é a área comercial. Vai fazer a venda do produto, vai fazer a instalação do equipamento todo no centro e vai prestar o serviço de manutenção". (ACTANTE I).

O interesse de participação das três empresas do projeto é comercial, ou seja, buscam vender seus produtos e serviços. Portanto, o objetivo de controlar práticas violentas dos quatro actantes discutidos anteriormente (Polícia Militar, Governo Municipal, ACIC e CDL) foi traduzido pelas empresas A, B e C como possibilidade de comercialização de produtos e serviços, o que permitiu o envolvimento de todos na construção da rede para a elaboração do projeto e a viabilização da fase experimental. Porém, para a consolidação do projeto como um todo, tornou-se necessário atrair novos actantes para a rede, conseguir recursos e garantir que a população traduzisse as câmeras de monitoramento eletrônico como controle das práticas violentas. A mídia escrita e eletrônica foi, então, envolvida.

Após um mês de fase experimental, o projeto foi apresentado à população pela mídia. Além das imagens da câmera de vídeo na rua e do monitoramento no computador operado por um policial militar, o Diretor de Defesa do Cidadão concedeu entrevistas às TVs e à imprensa escrita. Os quatros jornais locais noticiaram o evento, apresentando, cada qual, a foto de um policial militar monitorando imagens externas na tela de um computador. O jornal Diário do Iguaçu apresentou a seguinte manchete de capa:

Chapecó agora é vigiada 24 horas. Câmera instalada [...] tem capacidade para gerar imagem em uma distância de 600 metros, girando 360 graus. O projeto é instalar no município 12 câmeras, mas para isso será necessária parceria com o comércio e os bancos. O custo para a implantação 
é de aproximadamente R\$ 200 mil. O Objetivo principal é melhorar a qualidade do policiamento, dando suporte à Polícia Militar. (DIÁRIO DO IGUAÇU, 26/4/2005).

O jornal Diário da Manhã, a partir da manchete: "Sistema digital de segurança monitora centro de Chapecó", veicula uma reportagem completa com detalhes sobre o projeto, ressaltando que a câmera pode aumentar a imagem em dez vezes e informando sobre a área abrangida pelo projeto.

A reportagem do jornal Sul Brasil apresenta o título "Sistema de monitoramento é experimentado em Chapecó" e destaca o sucesso obtido no período de experimentação, a busca de parcerias para viabilizar a instalação do monitoramento, informando que "as imagens obtidas são transmitidas por cabo telefônico, sendo revertidas para o sistema digital. [...] a gravação digital não permite que as imagens sejam deturpadas" (SUL BRASIL, 26/4/2005).

Percebe-se, a partir das reportagens, que os diferentes jornais veicularam a concepção de monitoramento eletrônico da rede que sustenta o projeto, constituindo-se, assim, em mais um actante da mesma. E, como aponta Guattari e Rolnik (1993), a mídia é uma importante produtora de modos de pensar e agir, sendo um aliado fundamental para a aceitação do projeto pelas pessoas que vivem em Chapecó, contribuindo, assim, para aumentar a força mobilizadora das câmeras de vigilância.

\section{E que feitos essas câmeras podem produzir?}

Segundo o actante I, o funcionamento das câmeras de monitoramento possibilita a identificação e a vigilância das pessoas que circulam no trajeto alcançado e a prevenção do ato ilegal, através do acompanhamento 24 horas. Segundo actante J, o poder de vigilância das câmeras, permitida pela tecnologia atual de segurança, é muito grande:

Então se você instalar num raio grande, no centro da cidade ou em bairros, você consegue fiscalizar um bairro inteiro, quer dizer, se tiver uma estrutura de suporte atrás, você vai inibir o marginal, o delinquente, desses mais comuns pelo menos, você vai inibir, com certeza. Não tenha nem dúvida. [...] é um projeto tipo piloto. Se realmente funcionar, evidentemente que a gente vai fazer o projeto se expandir pela cidade toda. (ACTANTE J).

Para se compreender a visibilidade e a vigilância permitida pela nova tecnologia, é imprescindível considerar as ferramentas possibilitadas pelos estudos de Michel Foucault sobre a Sociedade Disciplinar. Para o autor:

O exercício da disciplina supõe um dispositivo que obrigue pelo jogo do olhar; um aparelho onde as técnicas que permitem ver induzem a efeitos de poder, e onde, em troca, os meios de coerção tornem claramente visíveis aqueles sobre quem se aplicam. [...] Ao lado da grande tecnologia dos 
óculos, das lentes, dos feixes luminosos, unida à fundação da física e da cosmologia novas, houve as pequenas técnicas das vigilâncias múltiplas e entrecruzadas, dos olhares que devem ver sem ser vistos [...] (FOUCAULT, 1995, p.153-154).

Foucault considera que o Panóptico de Bentham é o modelo dessa composição, pois articula visibilidade e vigilância:

O princípio é conhecido: na periferia uma construção em anel; no centro, uma torre; esta vazada de largas janelas que se abrem sobre a face interna do anel; a construção periférica é dividida em celas cada uma atravessando toda a espessura da construção; elas têm duas janelas, uma para o interior, correspondendo às janelas da torre; outra, que dá para o exterior, permite que a luz atravesse a cela de lado a lado. Basta então colocar um vigia na torre central, e em cada cela trancar um louco, um doente, um condenado, um operário ou um escolar. Pelo efeito da contraluz, pode-se perceber da torre, recortando-se exatamente sobre a claridade, as pequenas silhuetas cativas nas celas da periferia. [...] $\mathrm{O}$ dispositivo panóptico organiza unidades espaciais que permitem ver sem parar e reconhecer imediatamente. (FOUCAULT, 1995, p. 177).

O efeito mais importante do panóptico é induzir um estado permanente de visibilidade que assegura o funcionamento automático do poder, "fazer com que a vigilância seja permanente em seus efeitos, mesmo se é descontínua em sua ação" (FOUCAULT, 1995, p. 177-178). Pode-se perceber a busca dos mesmos efeitos na utilização das câmeras de monitoramento em Chapecó:

Por que o que acontece? Além de ter a marginalidade, que são os assaltos à mão armada, os riscos que você tem no trânsito [...], tanto parte de juventude, e até têm pessoas fora de juventude também, eles estão ligados ao álcool, drogas, e o que isso aí está se tornando? Está se tornando um caos. Então o que acontece? Tem que ter um número muito alto de policiamento, na área de segurança, para você poder atuar e corrigir essas falhas, esses acontecimentos [...]. E o sistema de monitoramento [...], ele vem a somar e ajudar nessa área aí. Porque a pessoa ela está dentro de um ambiente fechado, ela pode estar coordenando tudo isso e estar repassando as informações para o policiamento. [...] você estaria em cima sempre dos acontecimentos. (ACTANTE I).

Percebe-se que a vigilância descrita pelo actante I tem como diferencial, quando comparada à vigilância da sociedade disciplinar, "o fato de não se aplicar mais particularmente a uma pessoa suspeita, específica, mas antes a contextos lugares e espaços, períodos de tempo, redes, sistemas e categorias de pessoas" (PEDRO, 2005, p. 13). A figura de alguém que, a partir de uma tela de computa- 
dor, consegue vigiar o que se passa no exterior, em meio aberto, remete à noção de sociedade de controle, proposta por Deleuze. Para o autor, na sociedade de controle as formas de controle ao ar livre substituem as disciplinas que até então operavam em um sistema fechado:

Não há necessidade de ficção científica para se conceber um mecanismo de controle que dê a cada instante, a posição de um elemento em espaço abeto, animal em uma reserva, homem numa empresa (coleira eletrônica). Felix Guattari imaginou uma cidade onde cada um pudesse deixar seu apartamento, sua rua, seu bairro, graças a um cartão eletrônico (dividual) que abriria as barreiras; mas o cartão poderia também ser recusado em tal dia, ou entre tal e tal hora; o que conta não é a barreira, mas o computador que detecta a posição de cada um, lícita ou ilícita, e opera uma modulação universal. (DELEUZE, 1992, p. 224-225).

Pode-se dizer que as máquinas, em suas relações com os humanos, expressam e contribuem para a produção dos coletivos que as criam:

As antigas sociedades de soberania manejavam máquinas simples, alavancas, roldanas, relógios; mas as sociedades disciplinares recentes tinham por equipamento máquinas energéticas, com o perigo passivo da entropia e o perigo ativo da sabotagem. As sociedades de controle operam por máquinas de uma terceira espécie, máquinas de informática e computadores, cujo perigo passivo é a interferência, e, o perigo ativo, a pirataria e a introdução de vírus. (DELEUZE, 1992, p. 223).

$\mathrm{O}$ que pensam as pessoas que vivem em Chapecó sobre o projeto de instalação das câmeras de monitoramento eletrônico e da fase de experimentação? Houve alguma controvérsia por parte da população? Provocou alguma reação positiva ou negativa? Como essa discussão não foi feita por nenhum coletivo de Chapecó, aproveitou-se as entrevistas para perguntar às pessoas sobre esse tema. Descreve-se, a seguir, as principais idéias relatadas.

$\mathrm{O}$ actante $\mathrm{S}$ analisou aspectos técnicos do sistema, indicando haver corte de árvores na cidade, "de forma silenciosa", para viabilizar o seu funcionamento, pois há áreas descobertas pelo sistema de monitoramento, devido à presença de árvores que impedem a visão das câmeras de vídeo, produzindo "sombras" no monitoramento.

$\mathrm{O}$ actante I, envolvido com o projeto, afirmou que não surgiu polêmica com relação à instalação, em função de o sistema de monitoramento eletrônico estar presente em outras cidades e ser frequentemente noticiado pela mídia, produzindo certa naturalização ao ser associado automaticamente com tecnologia moderna e segurança. 
O actante R, também envolvido com o projeto, considerou não haver nenhuma controvérsia, mas "boa aceitação. Até porque é uma novidade. E realmente funciona, é muito bom isso aí. E inibe muito a prática de crimes, mesmo os pequenos delitos."

$\mathrm{O}$ actante $\mathrm{T}$ ressaltou o uso da tecnologia a serviço das pessoas, mas ressaltou que a população devia ser consultada porque afeta a sua privacidade. A Actante $\mathrm{V}$ afirmou que as câmeras invadiriam sua privacidade e controlariam apenas alguns tipos de crimes: "eles vão querer filmar quem vai roubar um 'somzinho' ali de um carro e tal e os outros tipos de roubos e de infrações? [...] é uma incoerência muito grande". Já o actante G ressaltou que as pessoas que realmente se preocupam com a segurança da cidade iriam concordar com a instalação do equipamento, pois a situação "está muito complicada".

Seriam, então, as dificuldades vividas no cotidiano que fariam com que pessoas desejassem esse tipo de controle, sentindo-se mais protegidas quando vigiadas? Os actantes $\mathrm{O}$ e $\mathrm{P}$ concordam com essa ideia: "As pessoas se sentem mais seguras ao saberem que estão sendo observados. As pessoas se cuidam ao saberem que estão sendo observados". (ACTANTE O). "Acho que tudo o que vier para controlar, controlar essa forma como as pessoas estão vivendo hoje seria beneficiário, vai beneficiar todo o mundo." (ACTANTE P).

Estaríamos nos rendendo, então, à ideia que circula de que, para nos sentirmos protegidos, é necessário sermos vigiados?

[...] para nos proteger, o controle indica que devemos renunciar a qualquer privacidade, pois nela pode residir o 'vírus' da insegurança, capaz de desestruturar o sistema, o que corresponderia à nossa própria aniquilação - enquanto sujeitos individuais, enquanto espécie, enquanto sociedade. Assim, expor-se ou não deixa de ser uma decisão subjetiva; ela é requerida por medidas de segurança que independem do sujeito e que, para operar de forma cada vez mais eficiente demanda cada vez mais 'dados'. (PEDRO; CHEVITARESE, 2003, p. 25-26).

Entretanto, há possibilidades de resistência frente a essa forma de controle, como aponta o actante B: "eu acho que à medida que a gente vai criando algumas formas de proteção, entre aspas, também vão sendo criadas formas de burlar essa proteção". Para Pedro e Chevitarese (2003, p. 27, grifo nosso), a resistência

[...] é uma ação política que, assim como o controle, se exerce em rede. Resistir é abrir possibilidades de subjetivação, desarticulando "modos de pensar e agir" já "assujeitados". Trata-se de desestabilizar os fluxos tecnológicos que nos produzem como sujeitos, para produzir com eles, outras formas inventivas de ser e de viver. 


\section{CONSIDERAÇÕES FINAIS}

Apesar de toda a mobilização envolvida pelo projeto, no período descrito, não se conseguiram recursos para a aquisição e instalação das câmeras de monitoramento. Houve também uma tentativa, por parte de seus articuladores, de apresentação do projeto para financiamento na Secretaria Nacional de Segurança Pública (SENASP), mas este não foi aprovado. No entanto, a mobilização não foi em vão, já que foram lançadas as justificativas da importância do monitoramento eletrônico e a legitimação da sua existência ao ser associado à vigilância e ao controle de práticas violentas. A efetivação do projeto aconteceu seis anos depois, em abril de 2011, por meio de um convênio estabelecido entre o município e o governo do estado de Santa Catarina, que instituiu o Programa Chapecó Segurança Máxima pela lei no 5989 (de 26 de abril de 2011) e teve como resultado a instalação de 186 câmeras de monitoramento em diferentes locais da cidade.

O estudo etnográfico acompanhou do projeto de monitoramento eletrônico em seus momentos e movimentos iniciais e possibilitou identificar conexões importantes entre atores e dar visibilidade ao processo de tradução que concebeu a nova tecnologia como um dispositivo de segurança na gestão de violências. Ainda, tornou visível que o controle, assim como a resistência, se exerce em rede, associando humanos e não humanos e produzindo subjetivações.

O significado da categoria violência em questão durante a pesquisa esteve vinculado predominantemente aos danos causados ao patrimônio público e privado: roubos, furtos, extorsão e depredação e que podem, em seu curso, ameaçar a vida das pessoas. Essa categoria conecta-se com a forma contemporânea de governar - a partir da insegurança e medo e por meio de dispositivos de segurança -, que compõe o que Foucault denominou de governamentabilidade, entre os quais se destacam as novas tecnologias de vigilância e controle como prevenção de violências.

No entanto, o estudo também evidenciou que o controle e a vigilância, no cotidiano, não se dão de forma linear, total ou eficaz. Há zonas de sombra que impedem a vigilância máxima: as câmeras de vídeo não conseguem atingir todos os lugares e regiões; as tecnologias de segurança também podem ser apreendidas pelas pessoas que se quer controlar, necessitando de inovações permanentes e há uma infinidade de possibilidades de resistir e subverter dispositivos de controle.

$\mathrm{O}$ evento acompanhado mostra também que, com relação à segurança, as regiões e as pessoas são diferentemente concebidas e pensadas no município: quais pessoas e espaços são protegidos e quais são vigiados? Quais são as pessoas, organizações e estabelecimentos que compõem a rede que pensa e decide a segurança no município e produz algum tipo de efeito na forma de governar a cidade?

A visibilidade do processo permite repensar práticas, políticas públicas e abre possibilidades para analisarmos redes vinculadas tanto à produção de violências como de segurança. Afinal, a rede não é algo já dado, mas sim construída e mantida a partir do trabalho constante de actantes e da tradução permanente dos diferentes interesses. Dessa forma, elementos podem ser articulados e desarticulados, fluxos podem ser estabilizados e desestabilizados. 


\section{Notas}

${ }^{1}$ A expressão caixa-preta, segundo Latour (2000, p. 14), "é utilizada em cibernética sempre que uma máquina ou um conjunto de comando se revela complexo demais. Em seu lugar, é desenhada uma caixinha preta, a respeito da qual não é preciso saber nada, senão o que dela entra e o que dela sai".

${ }^{2}$ Uso a palavra "violências", no plural, para ressaltar que faz menção a diversos significados e abrange diferentes situações.

${ }^{3}$ Chapecó é uma cidade de porte médio, localizada na região oeste de Santa Catarina.Sua população foi estimada em 189052 mil habitantes pelos dados do IBGE de 2010, sendo distribuída 93\% na área urbana e $7 \%$ na área rural.

${ }^{4}$ A Teoria Ator-Rede (TAR) situa-se no campo da Sociologia das Ciências e seus principais fundadores são Bruno Latour, Michel Callon e John Law.

${ }^{5}$ A denominação actante seguida de uma letra (selecionada ao acaso) é empregada para denominar as pessoas entrevistadas, de forma a destacar seu caráter de mediação tanto nos coletivos estudados, como na produção do texto.

\section{REFERÊNCIAS}

BECK, U. La société du Risque: sur la voie d'une autre modernité. Paris: Alto Aubier, 2001.

DELEUZE, G. Conversações. Rio de Janeiro: Editora 34, 1992.

GUATTARI, F. Caosmose: um novo paradigma estético. São Paulo: Ed. 34, 1992.

GUATTARI, F.; ROLNIK, S. Micropolíticas: cartografias do desejo. Petrópolis, (RJ): Vozes, 1993.

FOUCAULT, M. Vigiar e Punir: história da violência nas prisões. Petrópolis: Vozes, 1995.

FOUCAULT, M. Estratégia, poder-saber. Rio de Janeiro: Forense Universitária, 2003. Coleção Ditos \& Escritos IV.

KASTRUP, V. A rede: uma figura empírica da ontologia do presente. In: PARENTE, A. (Org.). Tramas da rede. Porto Alegre: Sulina, 2004.

PEDRO, R. M. L. R. Tecnologias de vigilância: um estudo psicossocial a partir da análise de controvérsias. In: XXIX ENCONTRO ANUAL DA ANPOC. 25 a 29 de outubro de 2005.

PEDRO, R. M. L. R.; CHEVITARESE, L. A questão da liberdade na sociedade tecnológica: por uma alegoria de Kafka a Dick. In: $27^{\circ}$ ENCONTRO ANUAL DA ANPOCS, CD-ROM, 2003.

LATOUR, B. Ciência em ação: como seguir cientistas e engenheiros sociedade afora. São Paulo: Editora UNESP, 2000. 
LATOUR, B. A esperança de Pandora. Bauru: EDUSC, 2001.

LATOUR, B. Changer de société: refaire de la sociologie. Paris: La Découverte, 2006.

Recebido em: 03 de julho de 2013

Aceito em: 11 de setembro de 2013 